Check for updates

Cite this: RSC Adv., 2017, 7, 41182

\title{
Rapid production of Pd nanoparticle by a marine electrochemically active bacterium Shewanella sp. CNZ-1 and its catalytic performance on 4- nitrophenol reduction
}

\begin{abstract}
Haikun Zhang and Xiaoke Hu iD *
Microbial recovery of $\mathrm{Pd}$ through $\mathrm{Pd}(॥)$ reduction is emerging as a clean alternative to traditional physical and chemical reclaiming treatments. Shewanella species are proven to be capable of excellent metal reduction properties and have thus drawn great attention for $\mathrm{Pd}(॥)$ reduction. So far, however, only Shewanella oneidensis MR-1 has been explored for Pd nanoparticles (Pd-NPs) production. In this study, we report a marine electrochemically active bacterium Shewanella sp. CNZ-1 with the ability for Pd-NPs generation in the presence of sodium lactate as an electron donor. SEM-EDX, TEM, FTIR, XRD and XPS analyses were performed to analyze the $\mathrm{Pd}(॥)$ reduction process and products. The results showed that Shewanella sp. CNZ-1 was more efficient than Shewanella oneidensis MR-1 in reducing Pd(॥) under current conditions. In addition, $\mathrm{Pd}(॥)$ reduction by $\mathrm{CNZ}-1$ was inhibited by low $\mathrm{pH}$ value (3-6) and high concentration of $\mathrm{NaCl}(3-9 \%)$, whereas $\mathrm{Pd}(॥)$ adsorption by CNZ-1 was unaffected by these factors. Further study showed that hydrogenase and some amides were involved in $\mathrm{Pd}(\mathrm{I})$ reduction by CNZ-1. Besides, Pd-NPs produced by CNZ-1 cells (bio $\mathrm{CNZ}_{-1}-\mathrm{Pd}-\mathrm{NPs}$ ) seemed more effective than those produced by MR-1 cells (bio MR-1 $_{1}-\mathrm{Pd}-\mathrm{NPs}$ ) in mediating 4-nitrophenol (4-NP) reduction by $\mathrm{NaBH}_{4}$. For the bio $_{\mathrm{CNZ}-1}$-Pd-NPs supplemented system, the $k_{1}$ (zero-order rate constant) values were 2.49-, 2.76- and 1.91-fold of the bio $\mathrm{MR}_{-1}-\mathrm{Pd}-\mathrm{NPs}$ supplemented system when the concentrations of NPs were $33 \mathrm{mg} \mathrm{L}^{-1}$, $83 \mathrm{mg} \mathrm{L}^{-1}$ and $167 \mathrm{mg} \mathrm{L}^{-1}$, respectively. The Pd recovery process by CNZ-1 is simple, efficient and environmentally friendly, and this biotechnology has potential practical application in treating mining wastewater.
\end{abstract}

\author{
Received 6th July 2017 \\ Accepted 16th August 2017 \\ DOI: $10.1039 / \mathrm{c} 7 \mathrm{ra0} 07438 \mathrm{~g}$ \\ rsc.li/rsc-advances
}

\section{Introduction}

Palladium (Pd) is a member of the precious platinum-group metals and possesses many unusual physicochemical and electronic properties. Based on these characteristics, Pd nanoparticles (Pd-NPs) have thus been widely used in biomedicine, chemicals, catalysts, sensors and biosensors. ${ }^{1-16}$ For example, Pd-NPs can be used as catalysts for a range of reactions, including alkene hydrogenation, ${ }^{1,2}$ Heck and Suzuki reactions, ${ }^{5,6} \mathrm{Cr}(\mathrm{vI})$ reduction, ${ }^{5,7}$ xenobiotics reduction ${ }^{8-11}$ and in fuel cells. ${ }^{12}$ In addition, Pd-NPs can be used in sensors and biosensors owing to their good electro-catalytic activity, and previous studies have showed their capability for the detection of $\mathrm{O}_{2},{ }^{13}$ hydrazine, ${ }^{14}$ formaldehyde,${ }^{15}$ and hydrogen peroxide. ${ }^{16}$ With the wide use of Pd-NPs, Pd certainly will be in short supply in the near future. For the sustainable use of the Pd resource, it is necessary to develop economical, environmentally friendly

Yantai Institute of Costal Zone Research, Chinese Academy of Sciences, Yantai 264000 , China.E-mail:xkhucas@163.com; Fax: +86 535 2109127; Tel: +86 5352109127 and efficient methods for Pd-recovery to meet the increasing demand of Pd.

Microbial recovery of $\mathrm{Pd}$ through $\mathrm{Pd}(\mathrm{II})$ reduction is emerging as a clean alternative to traditional physical and chemical reclaiming treatments. The advantages of this method are as follows: (i) the biomass can grow in large amounts rapidly and cheaply; (ii) this method is sensitive enough to recover Pd at ppm concentrations, which is often below the economic threshold of traditional recovery methods. ${ }^{17}$ According to previous studies, Pd-NPs that produced by microorganisms performed comparably to or better than the commercial catalyst during their applications in catalyzing hydrogenation, ${ }^{2}$ the environmental pollutants $\left(\mathrm{Cr}(\mathrm{vI}),{ }^{7}\right.$ halogenated aromatics, ${ }^{9,10}$ flame-retardants ${ }^{11}$ and so on) reduction, and the production of electricity in fuel cell. ${ }^{12}$ So far, many bacteria including Shewanella, ${ }^{10,18,19}$ Desulfovibrio, ${ }^{7,9,20}$ Cupriavidus, ${ }^{21,22}$ Pseudomonas, ${ }^{21,22}$ Paracoccus $^{21,22}$ and Escherichia ${ }^{17,22}$ genus etc. were proven to be capable of producing Pd-NPs inside or outside the cell. Among them, members of genus Shewanella are famous members of electrochemically active bacteria (EAB) that capable of using various metals/metalloids as terminal electron acceptors for 
their anaerobic respiration. ${ }^{23}$ It's reported that members of genus Shewanella are widely used to synthesize various metal NPs with great potentials for practical applications. ${ }^{22-24}$ Therefore, studies on production process and mechanism of Pd-NPs through genus Shewanella are attracting more and more attentions. ${ }^{10,18,19}$ However, to the best of our knowledge, only Shewanella oneidensis MR-1 was reported for Pd recovery ${ }^{18,19,22}$ and more Shewanella species need to be explored due to their potential practical application in producing Pd-NPs.

Shewanella species are thought to be of marine origin..$^{23}$ Marine ecosystems are an excellent resource of metal tolerant microorganisms. ${ }^{24}$ In recent years, marine bacteria are being explored as the potential bio-factories of metal tolerant microorganisms for synthesizing metallic NPs. ${ }^{25}$ In our previous studies, we isolated a marine electrochemically active bacterium Shewanella sp. CNZ-1 from the sediment of Bohai straits (China). Strain CNZ-1 was proven to be capable of extracellular reducing various $\mathrm{N}$-substituted aromatic compounds due to its good electrochemically activity. ${ }^{26}$ Accordingly, in this study, we further (i) investigated the ability of Shewanella sp. CNZ-1 for Pd(II) reduction under various factors; (ii) compared the biosynthesis process of Pd-NPs and their catalytic performance on 4-nitrophenol (4-NP) reduction between Shewanella sp. CNZ1 and Shewanella oneidensis MR-1 (type strain of Shewanella genus); (iii) preliminarily investigated the mechanism of Pd-NPs production through Shewanella sp. CNZ-1.

\section{Materials and methods}

\subsection{Chemicals}

$\mathrm{Na}_{2} \mathrm{PdCl}_{4}$ was used to prepare $\mathrm{Pd}(\mathrm{II})$ solution and it was purchased from Shanghai Macklin Biochemical Co., Ltd (China). 4-NP was purchased from Tokyo Chemical Industry Co., Ltd (Tokyo, Japan). All other reagents used in this study were of the highest analytical grade.

\subsection{Bacterial strains and growth conditions}

Shewanella sp. CNZ-1 (GenBank accession number KX384589, CNZ-1), an electrochemically active bacterium, was isolated from marine sediment by Zhang et al. (Bohai straits, N $38^{\circ}$ $30.29^{\prime}, \mathrm{E} 121^{\circ} 14.10^{\prime}$, China). ${ }^{26}$ Shewanella oneidensis MR-1 (MR-1), the type stain of Shewanella species, was obtained from Pro. Haichun Gao's lab (Zhejiang University, China). Luria-Bertani (LB) broth contains $5 \mathrm{~g} \mathrm{~L}^{-1}$ yeast extract, $10 \mathrm{~g} \mathrm{~L}^{-1}$ peptone, and $10 \mathrm{~g} \mathrm{~L}^{-1} \mathrm{NaCl}$. Mineral salt medium (MSM) contains $2 \mathrm{~g} \mathrm{~L}^{-1}$ sodium lactate, $1.0 \mathrm{~g} \mathrm{~L}^{-1} \mathrm{NH}_{4} \mathrm{Cl}, 0.8 \mathrm{~g} \mathrm{~L}^{-1}$ $\mathrm{Na}_{2} \mathrm{HPO}_{4}, 0.2 \mathrm{~g} \mathrm{~L}^{-1} \mathrm{KH}_{2} \mathrm{PO}_{4}, 0.2 \mathrm{~g} \mathrm{~L}^{-1} \mathrm{MgCl}_{2}, 0.1 \mathrm{~g} \mathrm{~L}^{-1} \mathrm{CaCl}_{2^{-}}$ $\cdot 2 \mathrm{H}_{2} \mathrm{O}, 20 \mathrm{~g} \mathrm{~L}^{-1} \mathrm{NaCl}(\mathrm{pH} 7.2){ }^{26}$

\subsection{Preparation of bio-Pd-NPs (under various conditions)}

After strain CNZ-1/MR-1 was cultured overnight in $100 \mathrm{~mL}$ LB broth in a rotary incubator shaker $\left(150 \mathrm{rpm}, 30^{\circ} \mathrm{C}\right)$, the CNZ-1/ MR-1 cells were harvested by centrifugation $(10000 \mathrm{rpm}, 5$ min) and washed twice with a sterile phosphate buffer solution (20 mM, pH 7.0). Then, the cell pellets were re-suspended with MSM for the following studies. The experimental systems utilised $135 \mathrm{~mL}$ serum bottles containing $100 \mathrm{~mL}$ deoxygenated sterile MSM and $0.28 \mathrm{mmol} \mathrm{L}^{-1} \mathrm{Pd}(\mathrm{II})$. The CNZ-1/MR-1 cells were added into the systems at a final concentration of $0.5 \mathrm{~g} \mathrm{~L}^{-1}$. After $10 \mathrm{~min}$ of $\mathrm{N}_{2}$ exposure and $24 \mathrm{~h}$ of incubation, bio-Pd-NPs were collected by centrifugation $(10000 \mathrm{rpm}$, $5 \mathrm{~min}$ ), washed with deionised water and finally dried in an oven at $60{ }^{\circ} \mathrm{C}$, respectively. Meanwhile, additional samples were taken at $10 \mathrm{~min}$ and $24 \mathrm{~h}$ with a sterile needle and a syringe for the analysis of the Pd species, respectively. In addition, various influence factors for Pd(II) reduction by CNZ1/MR-1, including pH (3-9, MSM adjusted by $1 \mathrm{M} \mathrm{HCl}$ and $\mathrm{NaOH})$, concentration of $\mathrm{NaCl}(2-9 \%)$ and initial $\mathrm{Pd}(\mathrm{II})$ concentration $\left(0.14-1.41 \mathrm{mmol} \mathrm{L} \mathrm{L}^{-1}\right)$, were systematically studied. To further investigate the mechanism of $\mathrm{Pd}(\mathrm{II})$ reduction through strain CNZ-1, Pd(II) reduction by heat-killed cells $\left(121{ }^{\circ} \mathrm{C}, 20 \mathrm{~min}\right)$ and $\mathrm{Cu}(\mathrm{II})$-treated cells $\left(0.4 \mathrm{mmol} \mathrm{L}^{-1}\right.$ $\mathrm{Cu}(\mathrm{II}), 30^{\circ} \mathrm{C}, 15 \mathrm{~min}$ ) were also performed.

\subsection{Characterisation of bio-Pd-NPs}

To identify the location of the reduced product, CNZ-1 cells attached with Pd-NPs were characterized using scanning electron microscopy-energy dispersive X-ray (SEM-EDX, Hitachi S-4800, Japan), transmission electron microscopy (TEM, JEM1400, Japan) and Fourier transform infrared spectroscopy (FTIR, Jasco FT/IR-4100, Japan). To identify the structure and valence state of Pd-NPs, the reduced products were further analysed using ultraviolet visible spectrometer (UV-Vis, PerkinElmer Lambda 365, USA), X-ray diffraction patterns (XRD, BRUKER D8 ADVANCE, Germany) and X-ray photoelectron spectroscopy (XPS, ESCALAB 250Xi, England). For SEM-EDX study, the bacterial cells associated with reduced product were filtered through micropore filtration unit, washed three times with normal saline and fixed with glutaraldehyde (3\%); it was then washed with Tris-HCl buffer followed by deionized water; the sample was finally dried with ethanol in ambient conditions, mounted on an aluminum stub. For TEM analysis, the samples were prepared as described Bunge et $a l .{ }^{21}$ For XRD, XPS and FTIR analyses, samples were obtained as following steps: (i) the cells were first exposed to $0.28 \mathrm{mmol} \mathrm{L}^{-1} \mathrm{Pd}$ (II) for $10 \mathrm{~min}$ and $24 \mathrm{~h}$ anaerobically; (ii) then separated by centrifugation at $10000 \mathrm{rpm}$ for $5 \mathrm{~min}$; (iii) the pellet was washed with deionised water and finally dried in an oven at $60^{\circ} \mathrm{C}$. The supernatant was used for subsequent UV-Vis analysis.

\subsection{Enhanced 4-NP reduction in the presence of bio-Pd-NPs}

The catalytic performance of bio-Pd-NPs was further evaluated. The electron donor and electron acceptor are $\mathrm{NaBH}_{4}$ and 4-NP, respectively. The total volume of the reaction mixture is $3 \mathrm{~mL}$, which contains 33-167 $\mathrm{mg} \mathrm{L}^{-1}$ bio-Pd-NPs, $1 \mathrm{~g} \mathrm{~L}^{-1} \mathrm{NaBH}_{4}$, and $150 \mathrm{mg} \mathrm{L}^{-1} 4$-NP in ultrapure water. Control assays without bioPd-NPs and with CNZ-1/MR-1 powders (drying in the oven at $60{ }^{\circ} \mathrm{C}$ ) only were also performed. The assay mixtures were incubated at room temperature. Each test was conducted three times and the mean was taken to eradicate any discrepancies. 


\subsection{Analytical methods}

The $\mathrm{Pd}$ (II) concentration was determined by inductively coupled plasma source mass spectrometer (ICP-MS). The cell and 4-NP concentrations were determined by UV-Vis spectrophotometer at their characteristic absorption peaks $(600 \mathrm{~nm}$ and $400 \mathrm{~nm}$, respectively). For analysis of reduction products, the supernatant was filtrated using $0.22 \mu \mathrm{m}$ filter membrane and then directly injected into the mass spectrometer. The mobile phase was methanol at $1.0 \mathrm{~mL} \min ^{-1}$. The reduction efficiency was calculated using eqn (I), as follows:

$$
\text { Reduction efficiency }(\%)=\frac{C_{\mathrm{i}}-C_{t}}{C_{\mathrm{i}}} \times 100 \%
$$

where $C_{\mathrm{i}}\left(\mathrm{mg} \mathrm{L}^{-1}\right)$ and $C_{t}\left(\mathrm{mg} \mathrm{L}^{-1}\right)$ are the initial and residual substrate at time zero and $t$, respectively; $t(\mathrm{~h})$ is the reaction time.

A zero-order model was applied to describe the kinetics of 4-NP reduction by $\mathrm{NaBH}_{4}$. The zero-order rate constant $k_{1}\left(\mathrm{~mol} \mathrm{~L}^{-1} \mathrm{~d}^{-1}\right)$ was determined according to the following eqn (II), where $t(\mathrm{~h}), C_{0}$ $\left(\mathrm{mg} \mathrm{L}^{-1}\right)$ and $C_{t}\left(\mathrm{mg} \mathrm{L}^{-1}\right)$ are the reaction time, the initial and residual 4-NP at time zero and $t$, respectively.

$$
C_{0}-C_{t}=k_{1} t
$$

A pseudo-first-order model was used to describe the kinetics of 4-NP reduction by $\mathrm{NaBH}_{4}$. The first-order rate constant $k_{2}\left(\min ^{-1}\right)$ was determined according to the following eqn (III), where $t(\mathrm{~h}), C_{0}\left(\mathrm{mg} \mathrm{L}^{-1}\right)$ and $C_{t}\left(\mathrm{mg} \mathrm{L}^{-1}\right)$ are the reaction time, the initial and residual $4-\mathrm{NP}$ at time zero and $t$, respectively.

$$
\ln C_{0} / C_{t}=k_{2} t
$$

\section{Results and discussion}

\subsection{Efficient Pd(II) reduction by Shewanella sp. CNZ-1}

The ability of Shewanella sp. CNZ-1 for Pd(II) bioreduction was first investigated (Fig. 1). After ten minutes of nitrogen exposure, the colour of $\mathrm{Pd}(\mathrm{II})$ solution changed from pale yellow to black brown in the CNZ-1 cells treated system $\left(\mathrm{S}_{\mathrm{CNZ}-1}\right)$. In comparison, the colour of MR-1 cells treated system $\left(\mathrm{S}_{\mathrm{MR}-1}\right)$ changed from pale yellow to light brown. The reason for this difference may be that $\operatorname{Pd}(\mathrm{II})$ reduction mechanism by MR-1 and CNZ-1 are quite different and we preliminarily discussed this question below. After $24 \mathrm{~h}$ of cultivation, the colour of both systems was turn into dark brown, indicating the production of Pd-NPs by CNZ-1 and MR-1 cells. The black appearance provided a visible signature for the formation of bio-Pd-NPs. The UV-Vis sorption results showed that a broad absorption band extending throughout the visible near-ultraviolet region $(\sim 300-500 \mathrm{~nm})$ was appeared, indicating the formation of Pd-NPs, which was consisted with previous studies. ${ }^{27,28}$

\subsection{Characterization of bio-Pd-NPs}

To confirm the reductive deposition of Pd(II) visually, SEM-EDX, TEM, XRD and XPS analyses were further performed. After

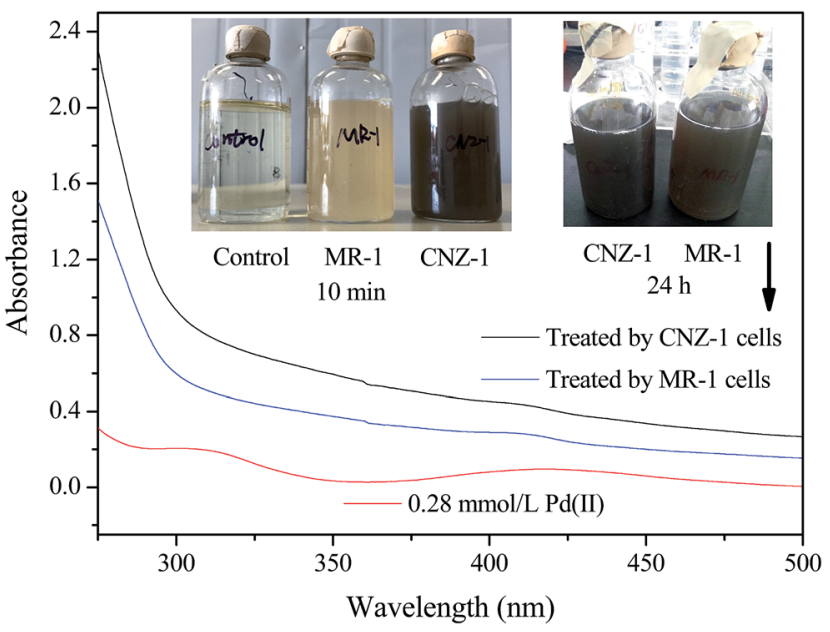

Fig. 1 UV-visible spectra of Pd(II) solution and supernatant of CNZ-1/ MR-1 cells treated systems ( $24 \mathrm{~h}$ ). The inset shows the colour change before and after reduction by CNZ-1/MR-1 cells (10 min and $24 \mathrm{~h}$, respectively).

exposed to $\mathrm{Pd}(\mathrm{II})$ solution for $24 \mathrm{~h}$, a number of Pd-NPs were observed on the surface of CNZ-1 cells (Fig. 2a). EDX analysis of Pd-NPs on the cell wall (insert checked pattern in Fig. 2a) showed that Pd peak was appeared and the weight percent of Pd was $\sim 15.38 \%$ (Fig. 2b), indicating that the possible location of Pd-NPs was the surface of CNZ-1 cells. TEM images of thin sections of CNZ-1 cells were obtained to further clarify the deposition location of Pd-NPs (Fig. 2c-e). The result showed that Pd-NPs were located in the periplasmic space of CNZ-1 cells. As indicated by Konishi et al., the space between the outer and inner membranes is a preferable location for easy recovery of biogenic metal NPs. ${ }^{29}$ The superficial deposition of Pd-NPs by CNZ-1 is beneficial for their recovery and potential use in interfacial bio-catalysis.

XRD patterns of different bio-Pd-NPs were presented in Fig. 3a, the diffraction peaks at $\sim 40^{\circ}, 46^{\circ}, 68^{\circ}, 81^{\circ}$ and $84^{\circ}$ could be indexed to the (111), (200), (220), (311) and (222) reflections of the fcc Pd (JCPDS 46-1043) structure. It addition, other diffraction peaks of bio-Pd-NPs may attributed to the protein on the surface of CNZ-1 cells (Fig. 3b). XPS was used to further characterize the chemical state information and electronic properties of bio-Pd-NPs. Samples taken from control system that without adding Pd(II) did not show Pd 3d spectra signal (data not shown). Fig. 3b revealed that after $10 \mathrm{~min}$ reduction by CNZ-1, Pd(II) ions that absorbed on the surface of CNZ-1 cells were partially reduced. After $24 \mathrm{~h}$ of reaction between CNZ-1 cells and Pd(II) ions, all attached Pd(II) ions were reduced to $\mathrm{Pd}^{0}$ NPs. As shown in Fig. $3 \mathrm{c}$, the binding energies of $\operatorname{Pd} 3 \mathrm{~d}_{5 / 2}$ and $\mathrm{Pd} 3 \mathrm{~d}_{3 / 2}$ had shifted due to the formation of Pd-NPs. In addition, all attached $\operatorname{Pd(II)}$ ions were also completely reduced in $\mathrm{S}_{\mathrm{MR}-1}$ (XPS data not shown). It is noticeable that the peak area of $\mathrm{Pd}^{0}$ in $\mathrm{S}_{\mathrm{CNZ}-1}$ is greater than that in $\mathrm{S}_{\mathrm{MR}-1}$, indicating more Pd-NPs were produced in $\mathrm{S}_{\mathrm{CNZ}-1}$ at $10 \mathrm{~min}$ (Fig. 3b and d). This finding was consistent with the different colour of $S_{\mathrm{CNZ}-1}$ and $S_{\mathrm{MR}-1}$ at $10 \mathrm{~min}$ as shown in Fig. 1. 

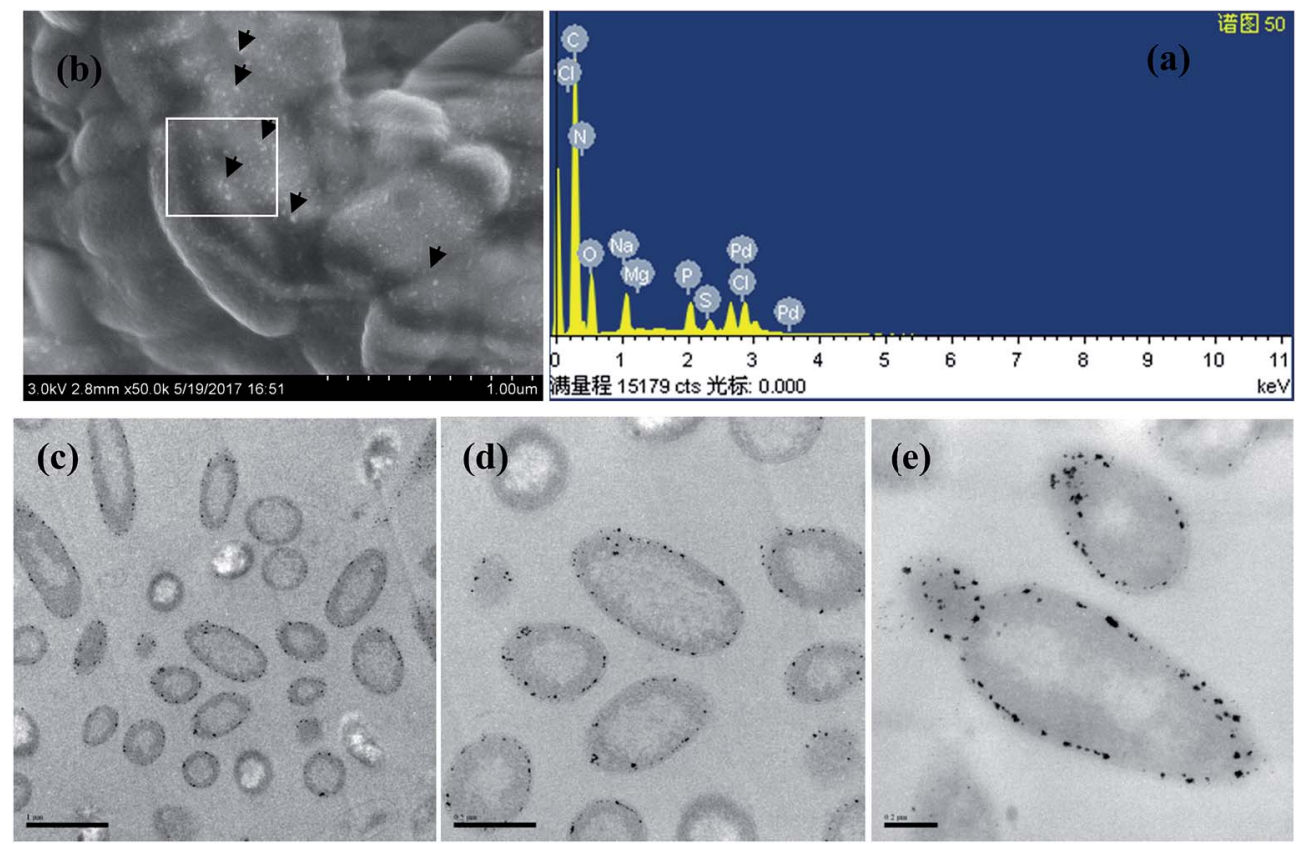

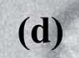

(d)

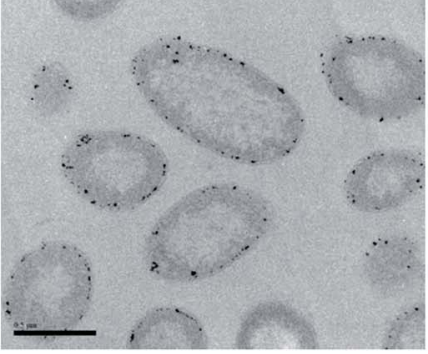

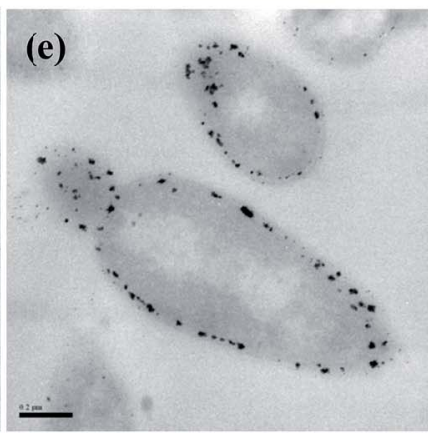

Fig. 2 SEM image of Pd attached CNZ-1 cells (24 h) (a); EDX image of the marked area in (a) and (b); TEM image of Pd attached CNZ-1 cells with different scale accuracy: $1 \mu \mathrm{m}$ (c), $0.5 \mu \mathrm{m}$ (d) and $0.2 \mu \mathrm{m}$ (e).

\subsection{Mechanism study}

According to the calculation of $\mathrm{Pd}$ (II) concentration in $\mathrm{S}_{\mathrm{CNZ}-1}$ and $\mathrm{S}_{\mathrm{MR}-1}$, we found that $\sim 36 \% \mathrm{Pd}$ (II) $\left(0.28 \mathrm{mmol} \mathrm{L}^{-1}\right)$ was reduced during in $10 \mathrm{~min}$ and $\sim 80 \% \operatorname{Pd}$ (II) was reduced in $24 \mathrm{~h}$ in $\mathrm{S}_{\mathrm{CNZ}-1}$; for $\mathrm{S}_{\mathrm{MR}-1}, \sim 8 \% \operatorname{Pd}(\mathrm{II})\left(0.28 \mathrm{mmol} \mathrm{L}^{-1}\right)$ was reduced during in 10 min and $\sim 72 \% \operatorname{Pd}(\mathrm{II})$ was reduced in $24 \mathrm{~h}$. In current experiment conditions, CNZ-1 was more efficient than MR-1 in Pd(II) reduction. It seemed that the mechanism for the reductive deposition of Pd(II) by CNZ-1 and MR-1 is rather different. At present, the mechanism of microbial $\mathrm{Pd}(\mathrm{II})$
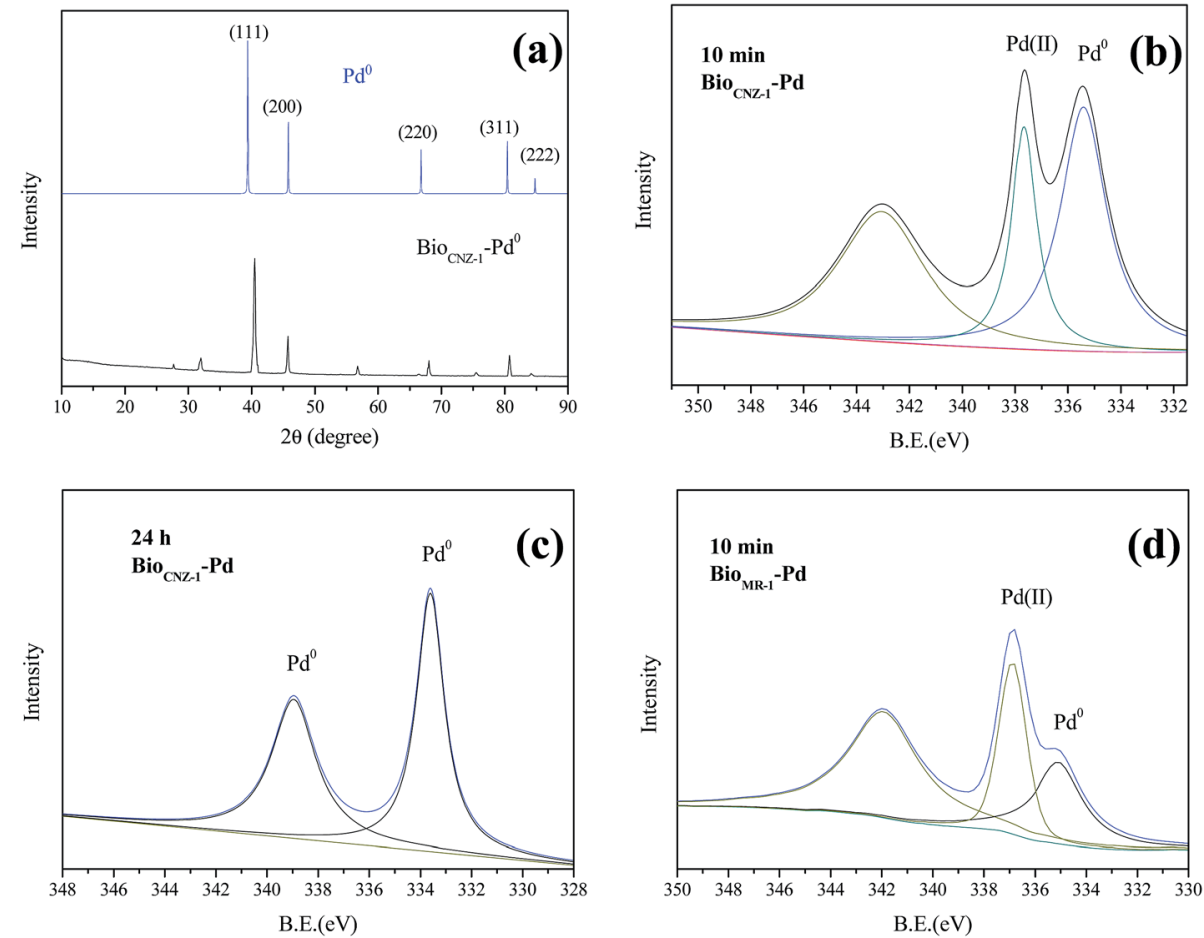

Fig. 3 The XRD spectra of bio ${ }_{\mathrm{CNZ}-1}-\mathrm{Pd}^{0}$ (a); the XPS spectra (Pd 3d) of bio $\mathrm{CNZ}_{-1}-\mathrm{Pd}^{0}$ at $10 \mathrm{~min}$ (b) and $24 \mathrm{~h}$ (c); the XPS spectra (Pd 3d) of bio $\mathrm{MR}^{-1^{-}}$ $\mathrm{Pd}^{0}$ at $10 \min (\mathrm{d})$. 
reduction was still unclear. Lloyd et al. reported that enzyme was involved in $\mathrm{Pd}(\mathrm{II})$ reduction by a sulfate-reducing bacterium. ${ }^{30} \mathrm{Ng}$ et al. reported that [NiFe]-hydrogenase HyaB could facilitate $\mathrm{Pd}(\mathrm{II})$ reduction by MR-1 in the presence of lactate as electron donors. ${ }^{19}$ However, Rotaru et al. found that Pd-NPs were still deposited on autoclaved cells of Cupriavidus necator that had no hydrogenase activity, suggesting a hydrogenase independent formation mechanism. Rotaru et al. also believe that amine group on the cells surface was important in $\operatorname{Pd}(\mathrm{II})$ recovery and even a non-enzymatic protein could stimulate $\mathrm{Pd}$ (II) reduction as efficiently as bacterial cells. ${ }^{31}$

In this study, the effect of hydrogenase in $\mathrm{Pd}(\mathrm{II})$ reduction through CNZ-1 was also studied and results were shown in Fig. 4. Four groups (group 1: CNZ-1 cells + Pd(II); group 2: CNZ-1 cells + Pd(II) + sodium lactate; group 3: hot-killed CNZ-1 cells + $\mathrm{Pd}(\mathrm{II})+$ sodium lactate; group 4: CNZ-1 cells $+\mathrm{Pd}(\mathrm{II})+$ sodium lactate $+\mathrm{Cu}(\mathrm{II}))$ were introduced to verify the roles of electron donor and hydrogenase during Pd(II) reduction as described by Lloyd et al. ${ }^{30}$ Results showed that the black brown precipitate can be observed obviously in the groups 1 and 2, which was not seen in groups 3 and 4. It's inferred that one or more hydrogenases were involved in the $\mathrm{Pd}(\mathrm{II})$ reduction by CNZ-1 in the presence of a lactate electron donor. Besides, since the $\operatorname{Pd}(\mathrm{II})$ reduction efficiencies by CNZ-1 and MR-1 were different under the same reaction conditions, it was speculated that the involved enzymes for Pd(II) reduction in CNZ-1 and MR-1 were different.

In addition, $\mathrm{Pd}(\mathrm{II})$ reduction by CNZ-1 was also observed without electron donor supplemented. A possible reason is that chemical groups of the extracellular secretion on CNZ-1 cell surface contributed to the $\mathrm{Pd}(\mathrm{II})$ reduction process. ${ }^{21}$ FTIR spectra can reveal possible physical and chemical interactions between $\operatorname{Pd}(\mathrm{II})$ and groups on the cell surface, we investigated this further with FTIR analysis and the results were shown in Fig. 5. As can be seen, some peaks decreased or disappeared after treated with CNZ-1 and MR-1 cells $10 \mathrm{~min}$ and $24 \mathrm{~h}$. These changes are centred at 1250-1750 $\mathrm{cm}^{-1}$, attributed to $\mathrm{N}-\mathrm{H}$ in plane bending and $\mathrm{C}-\mathrm{N}$ stretching of amides and carboxyl

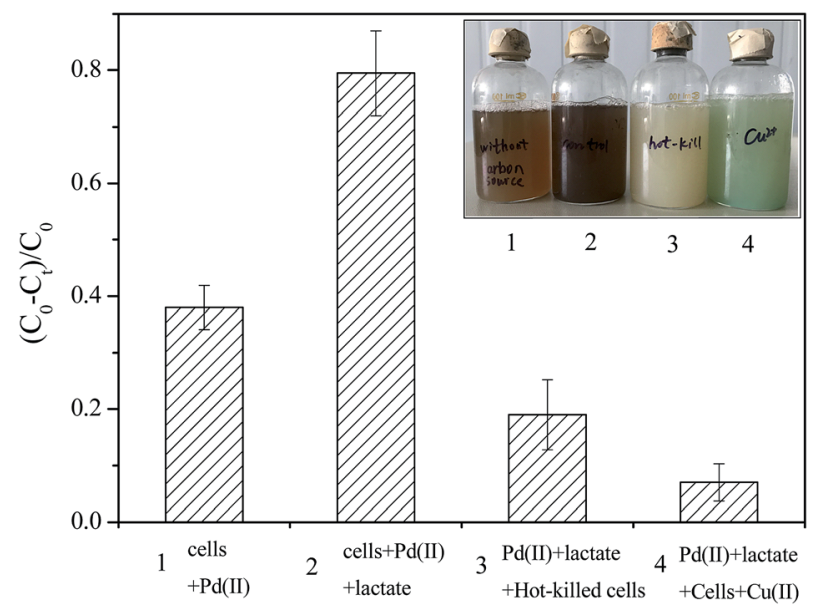

Fig. 4 The effects of $\mathrm{Cu}^{2+}$, hot-killed cells and lactate on $\mathrm{Pd}\left({ }^{\prime \prime}\right)$ reduction by $\mathrm{CNZ}-1$. groups. Previous study has reported that amine groups on surface of MR-1 cell were involved in $\mathrm{Pd}(\mathrm{II})$ reduction. ${ }^{31}$ In the FTIR spectra of CNZ-1 cells, the changes in above-mentioned feature absorption region are even more obvious than MR-1 cells. It's inferred that some cellular protein, mainly functional amine groups, ${ }^{31}$ were also involved in $\operatorname{Pd}(\mathrm{II})$ adsorption and reduction through CNZ-1. These findings imply that some structural properties of CNZ-1 cells account for the formation of Pd-NPs, which have implications for better use of these Shewanella strains.

Our current data imply that more general and structural properties of the cells account for the observed formation of $\operatorname{Pd}(0)$ nanoparticles among the bacterial strains investigated here. This may have implications for potential biotechnological applications, possibly also for processing increasingly toxic metals with bacteria not known for their dissimilatory metalreducing properties.

\subsection{Effects of various factors on $\mathrm{Pd}(\mathrm{II})$ reduction}

Previous study showed that MR-1 could reduce $\mathrm{Pd}(\mathrm{II})$ in the presence of various electron donors including $\mathrm{H}_{2}$, formate, lactate, pyruvate and ethanol. Moreover, the most efficient electron donor for $\mathrm{Pd}(\mathrm{II})$ reduction by MR-1 was proven to be lactate. ${ }^{10}$ Thus, $2 \mathrm{~g} \mathrm{~L}^{-1}$ sodium lactate was selected for further experiment in this study. The effect of initial Pd(II) concentration on the $\mathrm{Pd}(\mathrm{II})$ bioreduction efficiency by CNZ-1 was determined after $24 \mathrm{~h}$ (Fig. 6a). The addition of $\mathrm{Pd}$ (II) at 0.14, $0.28,0.42,0.56,0.84$ and $1.41 \mathrm{mmol} \mathrm{L}^{-1}$ result in 0.135 (97.1\%), 0.224 (80.0\%), 0.239 (57.1\%), 0.282 (50.0\%), 0.295 (34.9\%) and $0.282 \mathrm{mmol} \mathrm{L}^{-1}(20.0 \%) \mathrm{Pd}(\mathrm{II})$ removal in the presence of $0.5 \mathrm{~g} \mathrm{~L}^{-1} \mathrm{CNZ}-1$ cells. The results showed that the $\mathrm{Pd}(\mathrm{II})$ removal percentage decreased as initial Pd(II) concentration increased, indicating a relationship between initial Pd(II) concentration and biomass. Similarly, Yates et al. found that $\mathrm{Pd}(\mathrm{II})$ reduction efficiency by another electrochemically active bacterium Geobacter sulfurreducens decreased from 51\% to $34 \%$ as initial concentration of $\mathrm{Pd}$ (II) increased from 100 to $200 \mathrm{mg} \mathrm{L}^{-1}$, respectively. ${ }^{32}$ The effects of $\mathrm{pH}$ and $\mathrm{NaCl}$ concentration on $\mathrm{Pd}(\mathrm{II})$ reduction by $\mathrm{CNZ}-1$ were illustrated in Fig. 6b. It was found that $\mathrm{pH}$ value and $\mathrm{NaCl}$ concentration were important factors for CNZ-1 to producing Pd-NPs. When the $\mathrm{pH}$ value was less than 6 , the colour of $\mathrm{Pd}$ (II) solution did not change obviously. In our previous study, we found that strain CNZ-1 grew best under $\mathrm{pH}$ 7.3, whereas it failed to survive at $\mathrm{pH} 3.8 .^{26}$ When the $\mathrm{pH}$ value is higher than 6 , colour change could be observed easily in the reaction system due to the formation of Pd-NPs. In addition, Pd(II) reduction through CNZ-1 was inhibited by 3-9\% of NaCl. Yong et al. reported that formate hydrogenlyase was sensitive to $\mathrm{NO}_{3}{ }^{-}$and $\mathrm{Cl}^{-}$, we thus inferred that the activity of hydrogenase related to lactate was inhibited by low $\mathrm{pH}$ value and high $\mathrm{NaCl}$ concentration. ${ }^{33}$ However, it's notable that $\mathrm{Pd}(\mathrm{II})$ adsorption by CNZ-1 could be observed even at low $\mathrm{pH}$ value (3-6) and high $\mathrm{NaCl}$ concentrations (3-9\%). At $\mathrm{pH} 3.2$ and $9 \% \mathrm{NaCl}, \mathrm{Pd}(\mathrm{II})$ adsorption efficiency could still reach $\sim 84 \%$ and $\sim 74 \%$, respectively. 


\section{(a)}

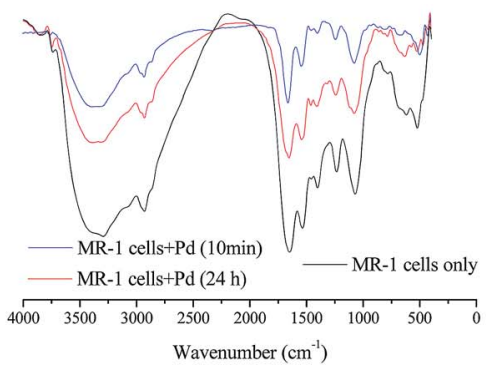

(b)

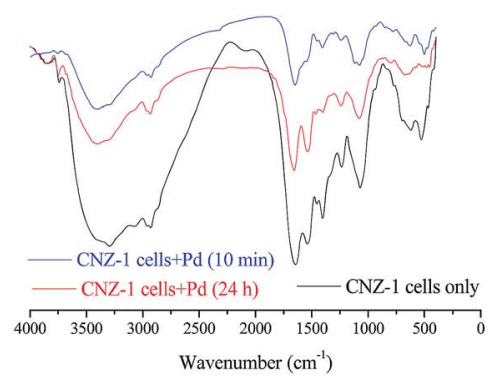

Fig. 5 The FTIR spectra of bio ${ }_{C N Z-1}-P^{0}(a)$ and biomR-1 $-P^{0}(b)$.

\subsection{Enhanced 4-NP reduction in the presence of bio-Pd-NPs}

The catalytic activity of bio-Pd-NPs was evaluated through 4-NP reduction in the presence of $\mathrm{NaBH}_{4}$. As $E_{0}$ for 4-nitrophenol/4aminophenol and $\mathrm{H}_{3} \mathrm{BO}_{3} / \mathrm{BH}_{4}{ }^{-}$is -0.76 and $-1.33 \mathrm{~V} v s$. SHE, respectively, this reaction could not proceed without additional catalyst. ${ }^{34}$ Thus, it was used to test the catalytic performance of bio-Pd-NPs in this study. Results showed that no reduction $(<3 \%)$ of 4 -NP occurred in control assays during 50 min whereas 4-NP was completely reduced during 20-30 min with the addition of bio CNZ-1 $\left.^{-P d-N P s ~(33-167 ~} \mathrm{mg} \mathrm{L}^{-1}\right)$. In comparison, catalytic reduction of 4-NP completely by bio MR-1 $^{-P d-N P s ~(33-167 ~} \mathrm{mg} \mathrm{L}^{-1}$ ) needed more than $40 \mathrm{~min}$. The reduction products were analyzed by mass spectrum, and 4-aminophenol was proven to be the primary product (data not shown). The zero-order and pseudofirst-order model were used to describe the kinetics of 4-NP reduction mediated by bio $_{\mathrm{CNZ}-1}-\mathrm{Pd}-\mathrm{NPs}$ (Fig. 7a and b) and bio $_{\text {MR-1 }}$-Pd-NPs (Fig. 7a and b), respectively. The kinetic parameters of the zero-order and pseudo-first-order equations were listed in Fig. 7. It was observed that the experimental data were well explained by the zero-order model in both reaction systems $\left(R^{2}>0.95\right)$. For the bio $_{\mathrm{CNZ}-1}$-Pd-NPs supplemented system, the $k_{1}$ (zero-order rate constant) values were 2.49-, 2.76- and 1.91-fold of the bio $_{\text {MR-1 }}$-Pd-NPs supplemented system when the concentrations of NPs were $33 \mathrm{mg} \mathrm{L}{ }^{-1}, 83 \mathrm{mg} \mathrm{L}^{-1}$ and $167 \mathrm{mg} \mathrm{L}^{-1}$, respectively. These results indicated that bio $_{\mathrm{CNZ}-1}-\mathrm{Pd}-\mathrm{NPs}$ have potential application in environmental pollutants control.

\subsection{Implications}

In this study, we have demonstrated that Shewanella sp. CNZ-1, a marine electrochemically active bacterium, is capable of adsorbing $\mathrm{Pd}(\mathrm{II})$ and producing Pd-NPs in the presence of sodium lactate. Shewanella species are proven to be capable of excellent metal reduction properties and have thus drawn great attention in $\operatorname{Pd}(\mathrm{II})$ reduction. ${ }^{\mathbf{1 8 , 1 9 , 2 3}}$ So far, however, only Shewanella oneidensis MR-1 was explored for $\mathrm{Pd}$ nanoparticles (Pd-NPs) production. In this study, we report a marine electrochemically active bacterium Shewanella sp. CNZ-1 with the ability for Pd-NPs generation in the presence of sodium lactate as electron donor. The current study was to contribute to the list of Shewanella strains with the ability for Pd-NPs production. In addition, CNZ-1 was found to be more efficient than MR-1 under current conditions $\left(2 \% \mathrm{NaCl}, \mathrm{pH} 7.2,2 \mathrm{~g} \mathrm{~L}^{-1}\right.$ sodium lactate as electron donor, $0.28 \mathrm{mmol} \mathrm{L}^{-1} \mathrm{Pd}(\mathrm{II})$ as electron acceptor). Compared to MR-1, CNZ-1 could produce Pd-NPs in a very short period of time (10 $\mathrm{min})$, which is beneficial for its further practical application.

The effects of various factors on Pd(II) reduction by CNZ-1 were studied and the optimal conditions for Pd recovery with highest efficiency were thereby assessed on all of basic factors. We noticed that excessive $\operatorname{Pd}(\mathrm{II})$ concentration (1.41 $\mathrm{mmol} \mathrm{L}^{-1}$ ), low $\mathrm{pH}$ values (3-6) and high concentration of $\mathrm{Cl}^{-}(3-9 \%)$ affected $\mathrm{Pd}(\mathrm{II})$ reduction by $\mathrm{CNZ}-1$, whereas nearly no influence on Pd(II) adsorption by CNZ-1. Because the enzymatic and genomic mechanisms of $\mathrm{Pd}(\mathrm{II})$ reduction by CNZ-1 are unknown yet, further studies need to be done for guiding the application of CNZ-1. On the basis of experiment results obtained in this study, a simple two-step process including Pd(II) adsorption and Pd(II) reduction was proposed for obtaining microbial produced Pd-NPs through CNZ-1 (Fig. 8). (a)

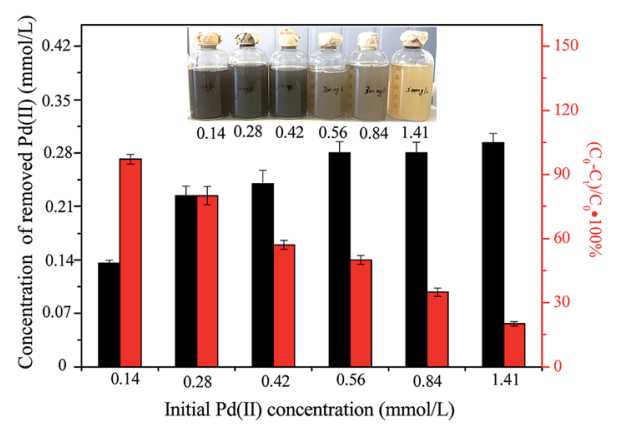

(b)

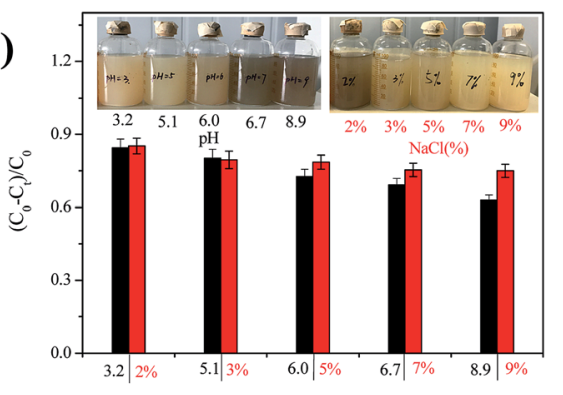

Fig. 6 The effects of initial $\mathrm{Pd}(॥)$ concentration (a), $\mathrm{pH}$ and $\mathrm{NaCl}$ concentration (b) on $\mathrm{Pd}(॥)$ reduction by CNZ-1. 
(a)

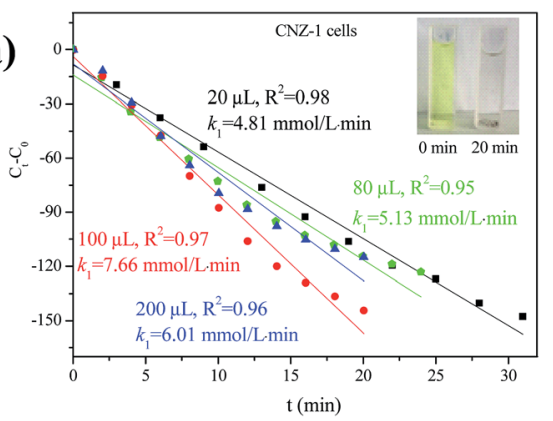

(c)

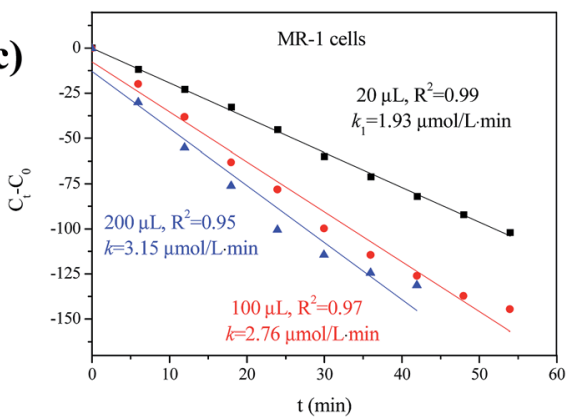

(b)

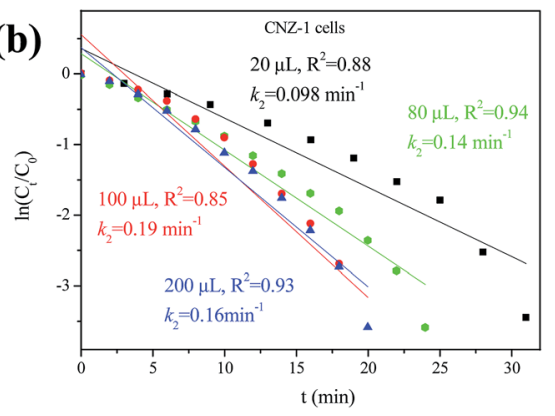

(d)

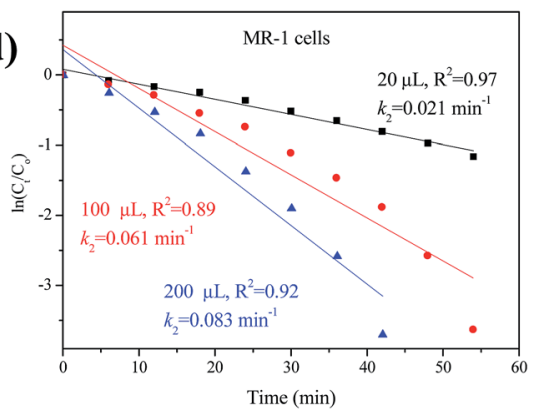

Fig. 7 4-NP reduction mediated by bio ${ }_{\mathrm{CNZ}-1}-\mathrm{Pd}^{0}(a, b)$ and bio ${ }_{\mathrm{CNZ}-1}-\mathrm{Pd}^{0}(\mathrm{c}, \mathrm{d})$ with different concentrations in the presence of $\mathrm{NaBH}_{4} ; \mathrm{plots}$ of $C_{t}$ $-C_{0}$ vs. time $(a, c)$ and $\ln \left(C_{t} / C_{0}\right)$ vs. time $(b, d)$ for the reduction of $4-\mathrm{NP}$ by $\mathrm{NaBH}_{4}$.

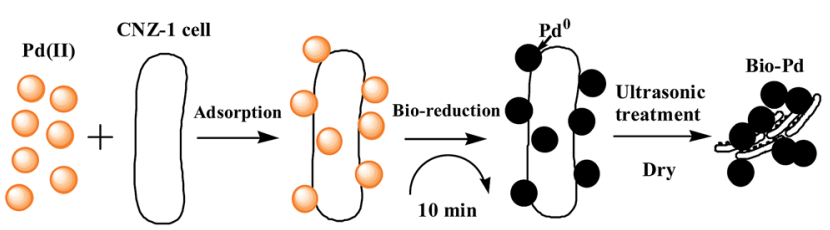

Fig. 8 A proposed two-step process for production of bio-Pd-NPs through CNZ-1.

\section{Conclusion}

In this study, we demonstrated that Pd-NPs could be produced rapidly by Shewanella sp. CNZ-1 cells with sodium lactate as electron donor. It is found that CNZ-1 was more efficient than Shewanella oneidensis MR-1 for producing Pd-NPs under current conditions. Pd(II) reduction by CNZ-1 was inhibited by low $\mathrm{pH}$ value and high concentration of $\mathrm{NaCl}$, whereas effects of the two factors on Pd(II) adsorption by CNZ-1 were not obviously. In addition, bio $_{\mathrm{CNZ}-1}$-Pd-NPs seemed more effective in mediating 4-NP reduction by $\mathrm{NaBH}_{4}$ compared to bio ${ }_{\mathrm{MR}-1}-\mathrm{Pd}-\mathrm{NPs}$. The Pd recovery process by CNZ- 1 is simple, efficient and environmental friendly, this biotechnology thus has potential application in treating mining wastewater.

\section{Conflicts of interest}

There are no conflicts to declare.

\section{Acknowledgements}

This subject was supported by the National Natural Science foundation of China (No. 51608519) and National Natural
Science foundation of Shandong Province, China (No. ZR2016EEB10). Thanks to Pro. Haichun Gao for providing Shewanella oneidensis MR-1.

\section{References}

1 Q. M. Kainz, R. Linhardt, R. N. Grass, G. Vilé, J. PérezRamírez, W. J. Stark and O. Reiser, Palladium nanoparticles supported on magnetic carbon-coated cobalt nanobeads: highly active and recyclable catalysts for alkene hydrogenation, Adv. Funct. Mater., 2014, 24, 2020-2027.

2 N. J. Creamer, I. P. Mikheenko, P. Yong, K. Deplanche, D. Sanyahumbi, J. Wood, K. Pollman, M. Merroun, S. Selenska-Pobell and L. E. Macaskie, Novel supported Pd hydrogenation bionanocatalyst for hybrid homogeneous/ heterogeneous catalysis, Catal. Today, 2007, 128, 80-87.

3 N. I. Hulkoti and T. C. Taranath, Biosynthesis of nanoparticles using microbes-a review, Colloids Surf., B, 2014, 121, 474-483.

$4 \mathrm{~J}$. Cui and L. Zhang, Metallurgical recovery of metals from electronic waste: a review, J. Hazard. Mater., 2008, 158, 228-256.

5 K. Deplanche, J. A. Bennett, I. P. Mikheenko, J. Omajali, A. S. Wells, R. E. Meadows, J. Wood and L. E. Macaskie, Catalytic activity of biomass-supported Pd nanoparticles: influence of the biological component in catalytic efficacy and potential application in 'green' synthesis of fine chemicals and pharmaceuticals, Appl. Catal., B, 2014, 147, 651-665.

6 Y. Li, Y. Dai, Z. Yang and T. Li, Controllable synthesis of palladium nanoparticles and their catalytic abilities in Heck and Suzuki reactions, Inorg. Chim. Acta, 2014, 414, 59-62. 
7 A. C. Humphries, K. P. Nott, L. D. Hall and L. E. Macaskie, Continuous removal of $\mathrm{Cr}(\mathrm{VI})$ from aqueous solutions catalyzed by palladized biomass of Desulfovibrio vulgaris, Biotechnol. Lett., 2004, 26, 1529-1532.

8 A. Safavi and S. Momeni, Highly efficient degradation of azo dyes by palladium/hydroxyapatite $/ \mathrm{Fe}_{3} \mathrm{O}_{4}$ nanocatalyst, $J$. Hazard. Mater., 2012, 201-202, 125-131.

9 V. S. Baxter-Plant, I. P. Mikheenko and L. E. Macaskie, Sulphate-reducing bacteria, palladium and reductive dehalogenation of chlorinated aromatic compounds, Biodegradation, 2003, 14, 83-90.

10 W. De Windt, P. Aelterman and W. Verstraete, Bioreductive deposition of palladium(0) nanoparticles on Shewanella oneidensis with catalytic activity towards reductive dechlorination of polychlorinated biphenyls, Environ. Microbiol., 2005, 7, 314-325.

11 S. Harrad, M. Robson, S. Hazrati, V. S. Baxter-Plant, K. Deplanche, M. D. Redwood and L. E. Macaskie, Dehalogenation of polychlorinated biphenyls and polybrominated diphenyl ethers using a hybrid bioinorganic catalyst, J. Environ. Monit., 2007, 9, 314-318.

12 P. Yong, M. Paterson-Beedle, I. P. Mikheenko and L. E. Macaskie, From bio-mineralisation to fuel cells: biomanufacture of Pd and Pt nanocrystals for fuel cell electrode catalyst, Biotechnol. Lett., 2007, 29, 539-544.

13 K. Jukk, N. Kongi, L. Matisen, T. Kallio, K. Kontturi and K. Tammeveski, Electroreduction of oxygen on palladium nanoparticles supported on nitrogen-doped graphene nanosheets, Electrochim. Acta, 2014, 137, 206-212.

14 P. K. Rastogi, V. Ganesan and S. Krishnamoorthi, Palladium nanoparticles decorated gaur gum based hybrid material for electrocatalytic hydrazine determination, Electrochim. Acta, 2014, 125, 593-600.

15 A. Safavi, N. Maleki, F. Farjami and E. Farjami, Electrocatalytic oxidation of formaldehyde on palladium nanoparticles electrodeposited on carbon ionic liquid composite electrode, J. Electroanal. Chem., 2009, 626, 75-79.

16 Y. Liu, G. Sun, C. Jiang, X. T. Zheng, L. Zheng and C. M. Li, Highly sensitive detection of hydrogen peroxide at a carbon nanotube fiber microelectrode coated with palladium nanoparticles, Microchim. Acta, 2014, 181, 63-70.

17 K. Deplanche, I. Caldelari, I. P. Mikheenko, F. Sargent and L. E. Macaskie, Involvement of hydrogenases in the formation of highly catalytic Pd (0) nanoparticles by bioreduction of Pd (II) using Escherichia coli mutant strains, Microbiology, 2010, 156, 2630-2640.

18 Y. Tuo, G. Liu, B. Dong, H. Yu, J. Zhou, J. Wang and R. Jin, Microbial synthesis of bimetallic PdPt nanoparticles for catalytic reduction of 4-nitrophenol, Environ. Sci. Pollut. Res., 2017, 24, 5249-5258.

19 C. K. Ng, T. K. C. Tan, H. Song and B. Cao, Reductive formation of palladium nanoparticles by Shewanella oneidensis: role of outer membrane cytochromes and hydrogenases, RSC Adv., 2013, 3, 22498-22503.

20 J. R. Lloyd, A. N. Mabbett, D. R. Williams and L. E. Macaskie, Metal reduction by sulphate-reducing bacteria: physiological diversity and metal specificity, Hydrometallurgy, 2001, 59, 327-337.

21 M. Bunge, L. S. Søbjerg, A. E. Rotaru, D. Gauthier, A. T. Lindhardt, G. Hause, K. Finster, P. Kingshott and R. L. Meyer, Formation of palladium (0) nanoparticles at microbial surfaces, Biotechnol. Bioeng., 2010, 107, 206-215.

22 S. De Corte, T. Hennebel, B. De Gusseme, W. Verstraete and N. Boon, Bio-palladium: from metal recovery to catalytic applications, Microb. Biotechnol., 2012, 5, 5-17.

23 D. Saffarini, K. Brockman, A. Beliaev, R. Bouhenni and S. Shirodkar, Shewanella oneidensis and extracellular electron transfer to metal oxides, Bacteria-Metal Interactions, Springer International Publishing, 2015, pp. 21-40.

24 P. Manivasagan, S. Y. Nam and J. Oh, Marine microorganisms as potential biofactories for synthesis of metallic nanoparticles, Crit. Rev. Microbiol., 2016, 42, 10071019.

25 M. Agnihotri, S. Joshi, A. R. Kumar, S. Zinjarde and S. Kulkarni, Biosynthesis of gold nanoparticles by the tropical marine yeast Yarrowia lipolytica NCIM 3589, Mater. Lett., 2009, 63, 1231-1234.

$26 \mathrm{H}$. Zhang and $\mathrm{X}$. $\mathrm{Hu}$, Catalytic reduction of NACs by nano $\mathrm{Fe}_{3} \mathrm{O}_{4}$ /quinone composites in the presence of a novel marine exoelectrogenic bacterium under hypersaline conditions, RSC Adv., 2017, 7, 11852-11861.

27 S. Momeni and I. Nabipour, A simple green synthesis of palladium nanoparticles with Sargassum alga and their electrocatalytic activities towards hydrogen peroxide, Appl. Biochem. Biotechnol., 2015, 176, 1937-1949.

28 T. Yonezawa, K. Imamura and N. Kimizuka, Direct preparation and size control of palladium nanoparticle hydrosols by water-soluble isocyanide ligands, Langmuir, 2001, 17, 4701-4703.

29 Y. Konishi, K. Ohno, N. Saitoh, T. Nomura, S. Nagamine, H. Hishida, Y. Takahashi and T. Uruga, Bioreductive deposition of platinum nanoparticles on the bacterium Shewanella algae, J. Biotechnol., 2007, 128, 648-653.

30 J. R. Lloyd, P. Yong and L. E. Macaskie, Enzymatic recovery of elemental palladium by using sulfate-reducing bacteria, Appl. Environ. Microbiol., 1998, 64, 4607-4609.

31 A. E. Rotaru, W. Jiang, K. Finster, T. Skrydstrup and R. L. Meyer, Non-enzymatic palladium recovery on microbial and synthetic surfaces, Biotechnol. Bioeng., 2012, 109, 1889-1897.

32 M. D. Yates, R. D. Cusick and B. E. Logan, Extracellular palladium nanoparticle production using Geobacter sulfurreducens, ACS Sustainable Chem. Eng., 2013, 1, 11651171.

33 P. Yong, N. A. Rowson, J. P. G. Farr, I. R. Harris and L. E. Macaskie, Bioreduction and biocrystallization of palladium by Desulfovibrio desulfuricans NCIMB 8307, Biotechnol. Bioeng., 2002, 80, 369-379.

34 S. K. Ghosh, M. Mandal, S. Kundu, S. Nath and T. Pal, Bimetallic Pt-Ni nanoparticles can catalyze reduction of aromatic nitro compounds by sodium borohydride in aqueous solution, Appl. Catal., A, 2004, 268, 61-66. 